\title{
Investigating gender differences for effectiveness and side effects of varenicline during smoking cessation treatment
}

\author{
Verena Castellani ${ }^{1}$ \\ (iD) Priscila Dib Gonçalves ${ }^{1}$ \\ (iD) João Mauricio Castaldelli-Maia, ${ }^{1,2,3}$ \\ (iD) André Malbergier ${ }^{1}$
}

1. Departamento e Instituto de Psiquiatria, Hospital das Clinicas HCFMUSP, Faculdade de Medicina, Universidade de São Paulo, São Paulo, SP, Brasil 2. Departamento de Neurociência, Escola de Medicina, Fundação do ABC, Santo André, SP, Brasil 3. Centro de Estudos em Saúde Mental do ABC, Santo André, SP, Brasil

\begin{abstract}
SUMMARY
Varenicline is a useful pharmacological option for smoking cessation. Unfortunately, there is a lack of studies on its effectiveness, retention, and side effects in low-and middle-income countries. The present study aimed to investigate gender differences regarding these outcomes in a Brazilian clinical sample $(n=124)$. The 12-week treatment protocol included six consultations with a psychiatrist and six sessions of cognitive-behavioral therapy. All subjects received varenicline on the first evaluation, following the standard posology for 12 weeks and instructions to stop smoking after the second week of treatment. Both Mini-International Neuropsychiatric Interview (MINI) Plus and Fagerstrom Test for Nicotine Dependence were applied at baseline. The UKU-Side Effects Rating Scale was administered at weeks 3, 7, and 11, and the Questionnaire of Smoking Urges-Brief at weeks 1, 5, and 9 to ascertain the side effects of the medication and craving, respectively. At the end of the 12-week treatment, abstinence was biochemically assessed. At months 6 and 12 after the treatment, follow-up telephone interviews were conducted to access nicotine abstinence. Short-and long-term abstinence and retention rates did not differ between genders. However, women presented more side effects than men, especially in the second half of the treatment. Increased dream activity, reduced duration of sleep, constipation, and weight loss were the most notable side effects. Despite women reporting more side effects than men, this difference did not influence the treatment success rates.
\end{abstract}

KEYWORDS: Smoking. Varenicline. Female. Women.

\section{INTRODUCTION}

Worldwide, 1.1 billion people are estimated to be smokers, and $80 \%$ of these smokers live in lowand middle-income countries ${ }^{1}$. Smoking is a public health issue, especially in these countries where the prevalence is not falling as it is in wealthy regions. This high prevalence tends to cause morbidity and mortality in lower-income regions. The epidemic of smoking among men had peaked and is now declining; however, the prevalence of smoking among women is rising in Brasil, where more than 10 million women are smoke ${ }^{\text {rs1,2, }}$.

Women who smoke have worse health outcomes than men ${ }^{3}$. Thus, providing evidence-based (pharmacological and non-pharmacological) smoking cessation 
treatment for women is a current public health issue. Investigating gender differences on varenicline outcomes is of utmost importance, as it is currently the most effective stand-alone medication available ${ }^{4}$ and seems to perform better in women ${ }^{5}$.

Despite reporting similar levels of nicotine dependence in psychometric measures, gender differences are observed in treatment settings ${ }^{6}$. Women tend to receive less pharmacological treatment ${ }^{7}$, even though they seek treatment more often ${ }^{8}$, and when on medication, report more side effects ${ }^{9}$. In addition, women report cravings more frequently, present a higher level of response to negative emotions ${ }^{10}$, and concern about weight gain ${ }^{11}$; all these factors contribute to an increased risk for relapse and may play an essential part in the fact that women are less successful in trying to quit smoking than men, particularly in the late abstinence period ${ }^{12}$.

Nicotine replacement therapy (NRT) seems to be more effective in men $^{13}$, but there is no consensus regarding gender differences when using bupropion ${ }^{14}$. In a recent meta-analysis, varenicline was more effective in women at 12 months of treatment. This discrepancy may have attenuated the differences usually seen in smoking cessation treatments ${ }^{5}$. This is a hypothesis that needs to be better understood and replicated in samples that include individuals from low- and middle-income countries.

Varenicline is an appropriate option for smoking cessation in women. However, there is a lack of studies on its effectiveness, retention, and side effects in low- and middle-income countries. The present study aimed to investigate gender differences regarding treatment effectiveness, retention, and side effects for varenicline during 12 weeks of treatment and 6and 12- month follow up in a Brazilian clinical sample.

\section{METHODS}

\section{Sample}

Participants were sampled among individuals voluntarily seeking treatment for nicotine dependence at the Institute of Psychiatry, Medical School, University of São Paulo, Brasil. Recruitment occurred from January 2009 to January 2011. The inclusion criteria were: being 18 years old or older, smoking at least ten cigarettes a day for the past year, and being nicotine-dependent according to the ICD-10 criteria. The exclusion criteria were the following: meeting criteria for current DSM-IV axis I disorder other than nicotine dependence, renal impairment, and women who were pregnant or nursing. A total of 145 subjects sought treatment, and 124 were eligible to participate in this study. Twelve individuals refused, and nine did not meet the ICD criteria. All participants provided written informed consent, and the procedures were approved by Hospital das Clinicas, Medical School Ethics Committee (protocol number 0226/08).

\section{Procedure}

The treatment protocol was composed of 12 weeks. The participants were assessed every 2 weeks by a trained psychiatrist. At each assessment, a questionnaire about smoking status ("have you been smoking in the prior 14 days?," "how many cigarettes do you smoke daily?," and "how many cigarettes have you smoked since your last appointment?" - if a participant reported having a puff, it was considered as one cigarette), use of medication ("did you take your medication in the last 2 weeks?", at each visit participants received medication for 2 weeks and showed the blister of the prior 2 weeks), side effects, general health issues, and psychiatric symptoms was completed by the patients. Carbon Monoxide (CO) was measured in every evaluation for comparison with the smoking self-report. Participants with expired CO readings between 0-6 ppm were considered "not smoking"; between 7-10 ppm may have smoked; and those with more than $11 \mathrm{ppm}$ were considered to be "smoking".

All subjects received varenicline on the first evaluation (titrated to $1 \mathrm{mg}$ twice daily for 8 days) for 12 weeks and were instructed to stop smoking during the second week of treatment. They attended six sessions of group behavioral therapy conducted by trained clinical psychologists. The UKU-Side Effects Rating Scale (UKU) was applied at weeks 3, 7, and 11 and the Questionnaire of Smoking Urges-Brief (QSU) at weeks 1,5 , and 9 to ascertain side effects of the medication and craving, respectively. At months 6 and 12 after the treatment, follow-up telephone interviews were conducted to access nicotine abstinence.

\section{Instruments}

The Mini-International Neuropsychiatric Interview (M.I.N.I.) Plus is a short-structured instrument for psychiatric diagnosis. It has similar results as the Structured Clinical Interview DSM Disorders (SCID) and Composite International Diagnostic Interview $(\text { CIDI })^{15}$. The M.I.N.I was applied at the first evaluation 
to rule out any psychiatry disorder other than nicotine dependence.

The Fagerstrom Test for Nicotine Dependence (FTND) is a simple, widely used test to assess the severity of nicotine dependence ${ }^{16}$.

UKU Side Effects Rating Scale was created to assess and rate the side effects of psychopharmacological medications ${ }^{17}$. Every question can be scored from 0 to 3 (none to severe side effects); total scores can vary from 0 to 150 points.

The Questionnaire of Smoking Urges-Brief (QSUBrief $)^{18}$ - is a craving assessment scale composed of 10 questions that the individual answers using a 7-point scale Likert scale. The QSU-B can be analyzed through the total sum of points.

\section{Statistical Analysis}

Data were summarized using frequency-distribution tables based on gender for all categorical variables. Survival analysis using the Kaplan-Meier method and the Wilcoxon test was applied to examine the association between gender and dropout over time. The $\chi^{2}$ test and Fisher's exact test were used to analyze abstinence at different moments of the treatment and at treatment conclusion (retention). All subjects who dropped out of the treatment were considered as relapsing in the survival analysis model, which considered these individuals missing data through censoring. All analyses were conducted using SAS version 9.2 and SPSS version 20. A statistical significance level of $5 \%$ was adopted.

\section{RESULTS}

The study sample included 124 participants, of which 79 (63.7\%) were women, and the mean ages were 36.5 for men and 40.3 for women $(p=0.07)$. Men started smoking at age 15.6 (average) and women at

TABLE 1. SOCIODEMOGRAPHIC VARIABLES BY GENDER

\begin{tabular}{|c|c|c|c|c|c|}
\hline & Female (n) & $\%$ & Male (n) & $\%$ & $\mathrm{p}$ \\
\hline \multicolumn{5}{|l|}{ Marital Status } & \multirow[t]{4}{*}{0.89} \\
\hline Married & 29 & 61.7 & 18 & 38.3 & \\
\hline Separated/Divorced & 7 & 58.33 & 5 & 41.67 & \\
\hline Widowed & 1 & 100 & 0 & 0 & \\
\hline \multicolumn{5}{|l|}{ Religion } & \multirow[t]{7}{*}{0.18} \\
\hline Catholic & 26 & 53.06 & 23 & 46.94 & \\
\hline Spiritualism & 8 & 61.54 & 5 & 38.46 & \\
\hline Protestant & 5 & 55.56 & 4 & 44.44 & \\
\hline Atheist & 2 & 66.67 & 1 & 33.33 & \\
\hline No formal religion & 35 & 77.78 & 10 & 22.22 & \\
\hline Others & 3 & 75 & 1 & 25 & \\
\hline \multicolumn{5}{|l|}{ Race } & \multirow[t]{5}{*}{0.13} \\
\hline White & 56 & 66.67 & 28 & 33.33 & \\
\hline African American & 7 & 77.78 & 2 & 22.22 & \\
\hline Mixed & 10 & 58.82 & 7 & 41.18 & \\
\hline Others & 4 & 33.33 & 8 & 66.67 & \\
\hline \multicolumn{5}{|l|}{ Education } & \multirow[t]{5}{*}{0.71} \\
\hline$<$ Middle School & 5 & 83.33 & 1 & 16.67 & \\
\hline$<$ High School & 8 & 72.73 & 3 & 27.27 & \\
\hline Some college & 31 & 60.78 & 20 & 39.22 & \\
\hline College graduate or higher & 35 & 62.5 & 21 & 37.5 & \\
\hline \multicolumn{5}{|l|}{ Working Status } & \multirow[t]{3}{*}{0.67} \\
\hline No & 18 & 69.23 & 8 & 30.77 & \\
\hline Yes & 61 & 62.24 & 37 & 37.76 & \\
\hline \multicolumn{5}{|l|}{ Monthly income (in Reais -Brazilian Currency) } & \multirow[t]{5}{*}{$<0.01$} \\
\hline$<700$ & 5 & 100 & 0 & 0 & \\
\hline 700 to 3499 & 37 & 82.22 & 8 & 17.78 & \\
\hline 3500 to 6999 & 20 & 47.62 & 22 & 52.38 & \\
\hline$>7000$ & 17 & 53.13 & 15 & 46.88 & \\
\hline
\end{tabular}


14.8 ( $\mathrm{p}=0.31)$. The demographic characteristics are displayed in Table 1. These characteristics did not differ significantly between gender, except for a higher monthly income among men $(p<0.01)$. There were no significant gender differences on FTND at baseline; craving reports (QSU score) at weeks 1, 5, and 9; smoking self-report ratings and $\mathrm{CO}$ breath measures among participants throughout the treatment.

In this study, no gender difference for treatment completion and dropout was observed. A total of 28 (62.2\%) men and 45 (57\%) women completed treatment. Likewise, there was no difference between gender in treatment dropout when survival analysis was used (Figure 1). Forty-nine patients who dropped out were reached by telephone. Among these, 18 participants (36.7\%) missed more than one psychotherapy or psychiatric evaluations, 11 (22.4\%) failed to give reasons for quitting treatment, 11 (22.4\%) discontinued treatment because they could not give up smoking, $6(12.2 \%)$ dropped out because of side effects, and 3 (6.1\%) had severe side effects and were excluded or chose to leave the study. Among these three participants, two developed severe depression, both having a previous history of depression (more than one year before the study) and one developed severe gastrointestinal symptoms.

No significant gender differences were found for abstinence at the end of the treatment (12 weeks, $62 \%$ for men versus $54 \%$ for women), and the telephone follow-ups. After 6 months, 38\% of the women and 51\% of the men remained abstinent. After 12 months, 30\% of the women and $38 \%$ of the men remained abstinent.

There were significant gender differences regarding side effects in almost all the assessments. Women had higher total UKU scores than men $(8.7,8.2$, and 7.0 points versus $6.3,3.8$, and 2.9 , respectively) in weeks 3,7 , and $11(p \leq 0.05)$. The most common side effects for both genders were: nausea/vomiting, reduced duration of sleep, increased dream activity, headaches, sleepiness, tension, and reduced salivation (see table 2). Considering all the assessments, women presented more increased dream activity, reduced duration of sleep, constipation, and weight loss. Gender differences in side effects at each evaluation are shown in Table 2. No differences were found during the assessment on week 3 . On week 7 , women presented more increased dream activity and constipation. On week 11 , women showed more nausea/vomiting.

TABLE 2. GENDER DIFFERENCES OF SIDE EFFECTS IN A BRAZILIAN CLINICAL SAMPLE OF SMOKING CESSATION USING VARENICLINE $(N=124)$

\begin{tabular}{|c|c|c|c|c|c|c|c|c|c|}
\hline & \multicolumn{3}{|l|}{ Week 3} & \multicolumn{3}{|l|}{ Week 7} & \multicolumn{3}{|l|}{ Week 11} \\
\hline & Men & Women & $p$ & Men & Women & $p$ & Men & Women & $\mathrm{p}$ \\
\hline Nausea/ vomiting & $27(67.5)$ & $42(72.4)$ & 0.85 & $15(57.7)$ & $30(75)$ & 0.27 & $5(26.3)$ & $19(55.9)$ & $0.05^{*}$ \\
\hline Reduced sleep time & $15(37.5)$ & $25(43.1)$ & 1 & $4(15.4)$ & $14(35)$ & 0.15 & $3(15.8)$ & $8(23.5)$ & 0.73 \\
\hline More dreams & $15(37.5)$ & $31(53.4)$ & 0.44 & $5(19.2)$ & $20(50)$ & $0.02^{*}$ & $3(15.8)$ & $12(35.3)$ & 0.21 \\
\hline Headaches & $15(37.5)$ & $23(39.6)$ & 0.85 & $3(11.5)$ & $11(27.5)$ & 0.22 & $2(10.5)$ & $13(38.2)$ & 0.06 \\
\hline Sleepiness/Sedation & $8(20)$ & $17(29.3)$ & 0.65 & $1(4.8)$ & $5(12.5)$ & 0.39 & $2(10.5)$ & $7(20.6)$ & 0.46 \\
\hline Reduced salivation & $7(17.5)$ & $21(36.2)$ & 0.13 & $4(15.4)$ & $10(25)$ & 0.54 & $1(5.3)$ & $9(26.5)$ & 0.07 \\
\hline Asthenia & $6(15)$ & $18(31)$ & 0.17 & $1(4.8)$ & $7(17.5)$ & 0.14 & $1(5.3)$ & $8(23.5)$ & 0.13 \\
\hline Constipation & $7(15)$ & $13(22.4)$ & 1 & $1(4.8)$ & $12(30)$ & $0.01^{*}$ & $2(10.5)$ & $7(20.6)$ & 0.46 \\
\hline Orthostatic Dizziness & $8(15)$ & $14(24.1)$ & 1 & $4(15.4)$ & $4(10)$ & 0.70 & $1(5.3)$ & $3(8.8)$ & 1 \\
\hline Tension/ Inner unrest & $5(12.5)$ & $2(3.4)$ & 0.10 & $4(15.4)$ & $10(25)$ & 0.54 & $2(10.5)$ & $8(23.5)$ & 0.30 \\
\hline Increased sleep time & $5(12.5)$ & $12(20.7)$ & 0.59 & $1(4.8)$ & $5(12.5)$ & 0.39 & $1(5.3)$ & $7(20.6)$ & 0.23 \\
\hline Polyuria/Polydipsia & $5(12.5)$ & $4(6.9)$ & 0.30 & $2(7.7)$ & $7(17.5)$ & 0.46 & $0(0)$ & $4(11.8)$ & 0.29 \\
\hline Concentration Problems & $4(10)$ & $13(22.4)$ & 0.28 & $2(7.7)$ & $6(15)$ & 0.47 & $2(10.5)$ & $8(23.5)$ & 0.29 \\
\hline Failing Memory & $4(10)$ & $12(20.7)$ & 0.29 & $2(7.7)$ & $8(20)$ & 0.29 & $1(5.3)$ & $8(23.5)$ & 0.13 \\
\hline Depression & $4(10)$ & $14(24.1)$ & 0.19 & $\mathrm{O}(0)$ & $5(15)$ & 0.15 & $1(5.3)$ & $5(14.7)$ & 0.40 \\
\hline Weight loss & $1(2.5)$ & $2(3.4)$ & 1 & $\mathrm{O}(0)$ & $11(27.5)$ & $<0.01^{\star}$ & $0(0)$ & $1(2.9)$ & 1 \\
\hline Weight gain & $3(7.5)$ & $6(10.34)$ & 1 & $1(4.8)$ & $9(22.5)$ & 0.07 & $2(10.5)$ & $5(14.7)$ & 1 \\
\hline Increased sweating & $2(5)$ & $2(3.4)$ & 0.64 & $0(0)$ & $6(15)$ & 0.07 & $0(0)$ & $2(5.9)$ & 1 \\
\hline Increased salivation & $3(7.5)$ & $3(5.17)$ & 0.67 & $1(4.8)$ & $4(10)$ & 0.64 & $2(10.5)$ & $1(2.9)$ & 0.29 \\
\hline
\end{tabular}




\section{DISCUSSION}

The present study aimed to investigate possible differences in smoking cessation treatment outcomes between men and women in a middle-income country. No differences were found for abstinence in the short- and long-term outcomes in this Brazilian sample. Treatment retention was also similar. However, women significantly presented more side effects than men, especially in the second half of the treatment. Increased dream activity, reduced duration of sleep, constipation, and weight loss were the most notable side effects for this outcome.

Women tend to have worse results than men when trying to quit smoking ${ }^{19}$. Despite having higher UKU side effects scores than men, women presented similar retention and quitting rates than men in the present study. This finding is consistent with results observed in large clinical trials ${ }^{20}$. The similar results among men and women - contrary to the idea that conventional smoking cessation programs are less effective in women ${ }^{21}$ - observed in our study raise the hypotheses that varenicline may attenuate those genders treatment differences, despite the more frequent and intense side effects among women. Similarly, a meta-analysis ${ }^{5}$ showed that men and women had similar nicotine abstinence rates when treated with varenicline. As women have worse outcomes than men when they are included in the placebo arms of trials, varenicline may compensate for the expected lower quitting rates among women ${ }^{5}$. Considering that women tend to seek treatment at higher rates than men in Brasil, as in many other countries, it would be essential to inform practitioners in smoking cessation services about varenicline's potential benefits for this gender ${ }^{22}$.

Retention rates did not differ between genders and were similar to those found in previous randomized controlled smoking cessation trials ${ }^{4}$ and naturalistic studies ${ }^{23,24}$.

In another study that focused on gender differences, women also reported more side effects when using varenicline. Similarly, such differences did not impact dropout rates ${ }^{9}$. Interestingly, side effects were classified as mild for both genders. This fact may explain why gender differences regarding side effects did not influence dropout rates and abstinence in the short- and long-term in this sample. Our study found a higher prevalence of side effects compared to others ${ }^{5}$. This may be due to the use of the UKU in

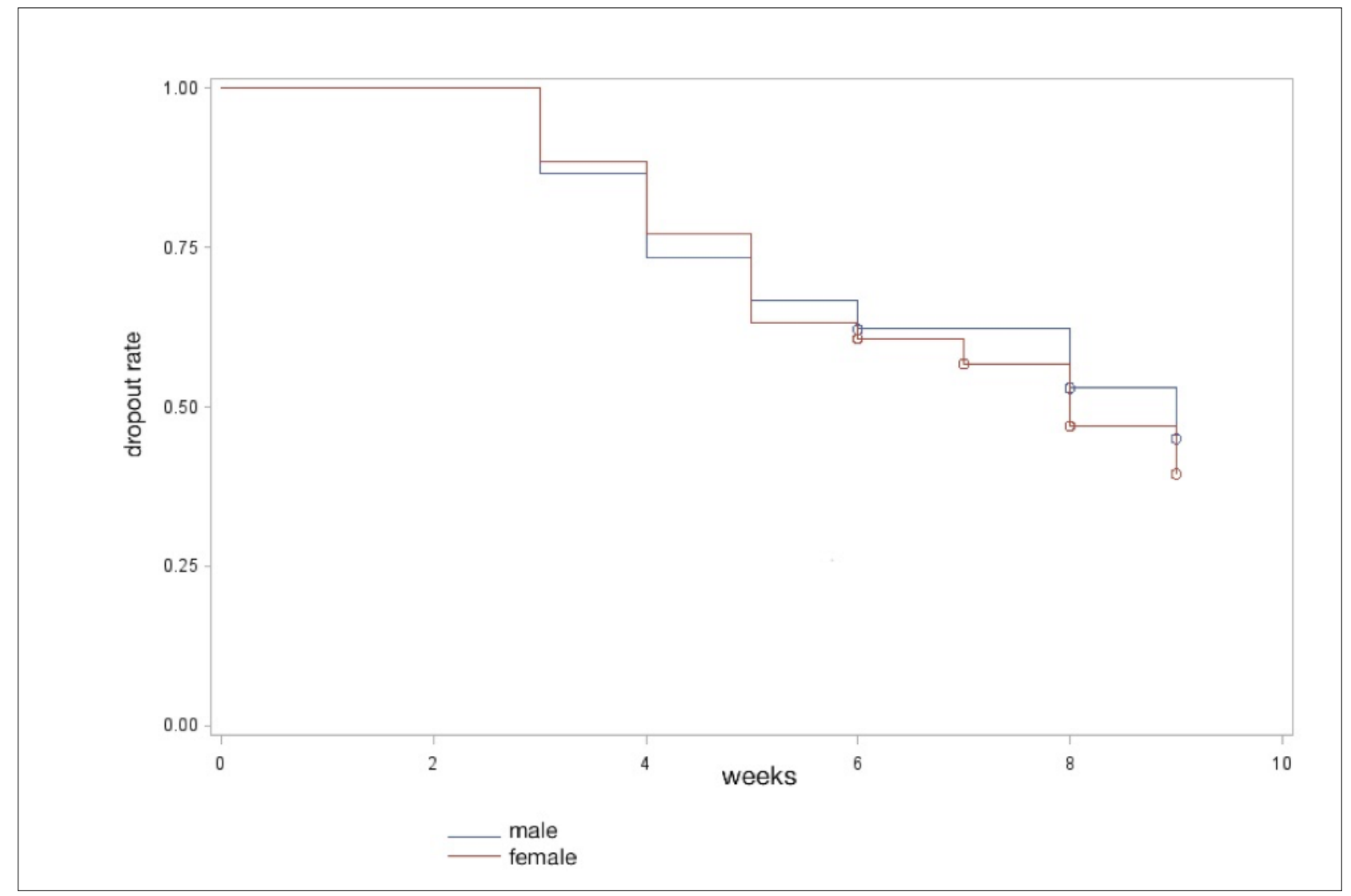


our study compared to the self-assessment reports or questionnaires with a list of varenicline's commonly referred side effects in the others. UKU appears to be more sensitive than self-reports and other scales.

\section{CONCLUSIONS}

In summary, although women reported more side effects than men when using varenicline, this difference did not influence the treatment success rates. On the contrary, varenicline may even compensate for the expected lower success rates in quitting smoking among women, which have been observed in other studies. A limitation of this study was its small sample size. Larger sample sizes are needed to replicate our findings.

\section{Authors Contributions}

VC designed the study, edited and critically reviewed the manuscript, and approved its final version. PDG designed the study, edited and critically reviewed the manuscript, and approved its final version. JMCM designed the study, edited and critically reviewed the manuscript, and approved its final version. AM designed the study, edited and critically reviewed the manuscript, and approved its final version.

\section{RESUMO}

A vareniclina é uma opção farmacológica útil para a cessação do tabagismo. Infelizmente, há uma ausência de estudos sobre a eficácia, retenção e efeitos colaterais para este medicamento em países de baixa e média renda. O presente estudo teve como objetivo investigar diferenças entre gênero em relação a esses desfechos em uma amostra clínica brasileira $(n=124)$. O protocolo de tratamento de 12 semanas incluiu seis consultas com um psiquiatra e seis sessões de psicoterapia cognitivo-comportamental. Todos os indivíduos receberam vareniclina na primeira avaliação, seguindo a posologia padrão por 12 semanas e instrução para parar de fumar a partir da segunda semana de tratamento. Tanto o Mini-International Neuropsychiatric Interview (MINI) Plus quanto o Teste de Fagerstrom para Dependência de Nicotina foram aplicados no início do estudo. A escala de efeitos colaterais (UKU-Side Effects Rating Scale) foi aplicada nas semanas 3, 7 e 11, e o Questionário Breve de Fissura (Questionnaire of Smoking Urges-Brief) nas semanas 1, 5 e 9 para investigar os efeitos colaterais da medicação e fissura, respectivamente. No final do tratamento de 12 semanas, a abstinência foi avaliada bioquimicamente. Aos 6 e 12 meses após o tratamento, foram realizadas entrevistas telefônicas de acompanhamento para acessar a abstinência de nicotina. As taxas de abstinência e retenção de curto e longo prazo não diferiram entre gêneros. No entanto, as mulheres apresentaram mais efeitos colaterais do que os homens, principalmente na segunda metade do tratamento. Aumento da atividade dos sonhos, redução da duração do sono, constipação e perda de peso foram os efeitos colaterais mais notáveis. Apesar de as mulheres relatarem mais efeitos colaterais que os homens, essa diferença não influenciou as taxas de sucesso do tratamento.

PALAVRAS CHAVE: Fumar. Vareniclina. Feminino. Mulheres.

\section{REFERENCES}

1. World Health Organization. WHO report on the global tobacco epidemic, 2017: monitoring tobacco use and prevention policies. Geneva: World Health Organization; 2017.

2. Malbergier A, Cardoso LR, Amaral RA, Santos VC. Gender parity and drug use: are girls catching up with boys ? Braz | Psychiatry. 2012;34(1):16-23.

3. Huxley RR, Woodward M. Cigarette smoking as a risk factor for coronary heart disease in women compared with men: a systematic review and meta-analysis of prospective cohort studies. Lancet. 2011;378(9799):1297-305

4. Anthenelli RM, Benowitz NL, West R, St Aubin L, McRae T, Lawrence D, et al. Neuropsychiatric safety and efficacy of varenicline, bupropion, and nicotine patch in smokers with and without psychiatric disorders (EAGLES): a double-blind, randomised, placebo-controlled clinical trial. Lancet. 2016;387(10037):2507-20.

5. McKee SA, Smith PH, Kaufman M, Mazure CM, Weinberger AH. Sex differences in varenicline efficacy for smoking cessation: a meta-analysis. Nicotine Tob Res. 2016;18(5):1002-11.

6. Castaldelli-Maia JM, Martins SS, Storr CL, Viana MC, Andrade LH, Andrade AG. Investigating the dimensional diagnosis of ICD-11 nicotine dependence. Psychol Addict Behav. 2018;32(4):415-25.

7. Steinberg MB, Akincigil A, Delnevo CD, Crystal S, Carson JL. Gender and age disparities for smoking-cessation treatment. Am J Prev Med. 2014;30(5):405-12.
8. Huang $Y$, Britton J, Hubbard R, Lewis S. Who receives prescriptions for smoking cessation medications? An association rule mining analysis using a large primary care database. Tob Control. 2013;22(4):274-9.

9. Halperin AC, McAfee TA, Jack LM, Catz SL, McClure JB, Deprey TM, et al. Impact of symptoms experienced by varenicline users on tobacco treatment in a real world setting. J Subst Abuse Treat. 2009;36(4):428-34.

10. Jarvis MI, Cohen JE, Delnevo CD, Giovino GA. Dispelling myths about gender differences in smoking cessation: population data from the USA, Canada and Britain. Tob Control. 2013;22(5):356-60.

11. Lombardi EM, Prado GF, Santos UP, Fernandes FL. Women and smoking: risks, impacts, and challenges. J Bras Pneumol. 2011;37(1):118-28.

12. Piper ME, Cook JW, Schlam TR, Jorenby DE, Smith SS, Bolt DM, et al. Gender, race, and education differences in abstinence rates among participants in two randomized smoking cessation trials. Nicotine Tob Res. 2010;12(6):647-57.

13. Cepeda-Benito A, Reynoso JT, Erath S. Meta-analysis of the efficacy of nicotine replacement therapy for smoking cessation: differences between men and women. J Consult Clin Psychol. 2004;72(4):712-22.

14. Scharf D, Shiffman S. Are there gender differences in smoking cessation, with and without bupropion? Pooled-and meta-analyses of clinical trials of Bupropion SR. Addiction. 2004;99(11):1462-9

15. Sheehan DV, Lecrubier $Y$, Sheehan KH, Amorim P, Janavs J, Weiller E, et al. The Mini-International Neuropsychiatric Interview (M.I.N.I.): the 
development and validation of a structured diagnostic psychiatric interview for DSM-IV and ICD-10. I Clin Psychiatry. 1998;59(Suppl 20):22-33.

16. Fagerstrom KO, Schneider NG. Measuring nicotine dependence: a review of the Fagerstrom Tolerance Questionnaire. J Behav Med. 1989;12(2):159-82.

17. Lingjaerde O, Ahlfors UG, Bech P, Dencker SJ, Elgen K. The UKU side effect rating scale: a new comprehensive rating scale for psychotropic drugs and a cross-sectional study of side effects in neuroleptic-treated patients. Acta Psychiatr Scand Suppl. 1987;334:1-100.

18. Cox LS, Tiffany ST, Christen AG. Evaluation of the brief questionnaire of smoking urges (QSU-brief) in laboratory and clinical settings. Nicotine Tob Res. 2001;3(1):7-16.

19. Smith PH, Bessette Al, Weinberger AH, Sheffer CE, McKee SA. Sex/gender differences in smoking cessation: a review. Prev Med. 2016;92:135-40.

20. Liberman JN, Lichtenfeld MJ, Galaznik A, Mastey V, Harnett J, $\mathrm{Zou} \mathrm{KH}$, et al. Adherence to varenicline and associated smoking cessation in a community-based patient setting. J Manag Care Pharm. 2013;19(2):125-31.

21. Ortner R, Schindler SD, Kraigher D, Mendelsohn A, Fischer G. Women addicted to nicotine. Arch Womens Ment Health. 2002;4(4):103-9.

22. Rodrigues NC, Neves RD, Mendes DS, Mendes CP, Martins IH, Reis IN, et al. Profile of Brazilian smokers in the National Program for Tobacco Control. Braz | Psychiatry. 2015;37(2):150-4.

23. Castaldelli-Maia JM, Carvalho CF, Armentano F, Frallonardo FP, Alves TC, Andrade AG, et al. Outcome predictors of smoking cessation treatment provided by an addiction care unit between 2007 and 2010. Rev Bras Psychiatry. 2013;35(4):338-46.

24. Loreto AR, Carvalho CFC, Frallonardo FP, Ismael F, Andrade AG, Castaldelli-Maia IM. Smoking cessation treatment for patients with mental disorders using CBT and combined pharmacotherapy. J Dual Diagn. 2017;13(4):238-46. 